NASA/TM-2004-213039

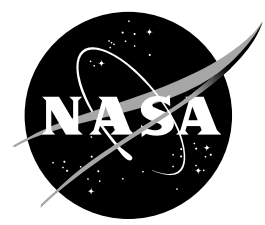

\title{
Microgravity Environment on the International Space Station
}

Richard DeLombard

Glenn Research Center, Cleveland, Ohio

Kenneth Hrovat and Eric Kelly

ZIN Technologies, Inc., Brook Park, Ohio

Kevin McPherson

Glenn Research Center, Cleveland, Ohio 
Since its founding, NASA has been dedicated to the advancement of aeronautics and space science. The NASA Scientific and Technical Information (STI) Program Office plays a key part in helping NASA maintain this important role.

The NASA STI Program Office is operated by Langley Research Center, the Lead Center for NASA's scientific and technical information. The NASA STI Program Office provides access to the NASA STI Database, the largest collection of aeronautical and space science STI in the world. The Program Office is also NASA's institutional mechanism for disseminating the results of its research and development activities. These results are published by NASA in the NASA STI Report Series, which includes the following report types:

- $\quad$ TECHNICAL PUBLICATION. Reports of completed research or a major significant phase of research that present the results of NASA programs and include extensive data or theoretical analysis. Includes compilations of significant scientific and technical data and information deemed to be of continuing reference value. NASA's counterpart of peerreviewed formal professional papers but has less stringent limitations on manuscript length and extent of graphic presentations.

- TECHNICAL MEMORANDUM. Scientific and technical findings that are preliminary or of specialized interest, e.g., quick release reports, working papers, and bibliographies that contain minimal annotation. Does not contain extensive analysis.

- CONTRACTOR REPORT. Scientific and technical findings by NASA-sponsored contractors and grantees.
- CONFERENCE PUBLICATION. Collected papers from scientific and technical conferences, symposia, seminars, or other meetings sponsored or cosponsored by NASA.

- SPECIAL PUBLICATION. Scientific, technical, or historical information from NASA programs, projects, and missions, often concerned with subjects having substantial public interest.

- TECHNICAL TRANSLATION. Englishlanguage translations of foreign scientific and technical material pertinent to NASA's mission.

Specialized services that complement the STI Program Office's diverse offerings include creating custom thesauri, building customized databases, organizing and publishing research results ... even providing videos.

For more information about the NASA STI Program Office, see the following:

- Access the NASA STI Program Home Page at http://www.sti.nasa.gov

- E-mail your question via the Internet to help@sti.nasa.gov

- Fax your question to the NASA Access Help Desk at 301-621-0134

- Telephone the NASA Access Help Desk at 301-621-0390

- Write to:

NASA Access Help Desk

NASA Center for AeroSpace Information 7121 Standard Drive

Hanover, MD 21076 
NASA/TM-2004-213039

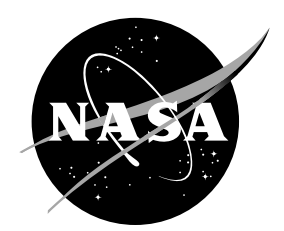

\section{Microgravity Environment on the International Space Station}

Richard DeLombard

Glenn Research Center, Cleveland, Ohio

Kenneth Hrovat and Eric Kelly

ZIN Technologies, Inc., Brook Park, Ohio

Kevin McPherson

Glenn Research Center, Cleveland, Ohio

Prepared for the

42nd Aerospace Sciences Meeting and Exhibit

sponsored by the American Institute of Aeronautics and Astronautics

Reno, Nevada, January 5-8, 2004

National Aeronautics and

Space Administration

Glenn Research Center 
Available from

NASA Center for Aerospace Information 7121 Standard Drive

Hanover, MD 21076
National Technical Information Service 5285 Port Royal Road Springfield, VA 22100

Available electronically at http://gltrs.grc.nasa.gov 


\title{
MICROGRAVITY ENVIRONMENT ON THE INTERNATIONAL SPACE STATION
}

\author{
Richard DeLombard \\ National Aeronautics and Space Administration \\ Glenn Research Center \\ Cleveland, Ohio 44135 \\ Kenneth Hrovat and Eric Kelly \\ ZIN Technologies, Inc. \\ Brook Park, Ohio 44142 \\ Kevin McPherson \\ National Aeronautics and Space Administration \\ Glenn Research Center \\ Cleveland, Ohio 44135
}

\begin{abstract}
The International Space Station is being assembled on-orbit to serve as a research platform for the next twenty years. A primary feature of this research platform will be its microgravity environment - an environment in which the effects of gravity are drastically reduced. A physical environment with very low-levels of acceleration and vibration has been accomplished by both the free fall associated with orbital flight and the design of the International Space Station. The International Space Station design has been driven by a long-standing, high-level requirement for a microgravity mode of operation.

Various types of data are gathered when science experiments are conducted, with common variables being temperature, pressure, voltage, and power. The acceleration levels experienced during operation should be factored into the analysis of the experiment results of most microgravity experiments. To this end, the NASA Fundamental Microgravity Research in the Physical Sciences program has had the Space Acceleration Measurement System recording the acceleration levels to support microgravity researchers for over twelve years of Shuttle missions, three years on Mir, and now nearly three years of International Space Station operations.

The Fundamental Microgravity Research in the Physical Sciences program also supports the Principal Investigator Microgravity Services project to assist the principal investigators with their analysis of the acceleration (microgravity) environment. The Principal
\end{abstract}

Investigator Microgravity Services project provides cataloged data, periodic analysis summary reports, specialized reports for experiment teams, and real-time data in a variety of user-defined formats. Characterization of the various microgravity carriers (e.g. Shuttle and International Space Station) is also accomplished for the experiment teams.

In the future, the Principal Investigator Microgravity Services project will provide a detailed predictive analysis of the microgravity environment for particular payloads in specified locations. This will assist greatly in the operational payload planning process. In addition, a neural-network-based system is planned which will automatically interpret the environment in real-time and present the results to users in an easily understood format.

Presented in this paper will be a short description of how microgravity disturbances may affect some experiment classes, a snapshot of the microgravity environment, and a view into how well the space station is expected to meet the user requirements.

\section{ABBREVIATIONS AND ACRONYMS}

ARIS Active Rack Isolation System

ICE ISS Characterization Experiment

ISS International Space Station

MAMS Microgravity Acceleration Measurement System

NASA National Aeronautics and Space Administration

PIMS Principal Investigator Microgravity Services

SAMS Space Acceleration Measurement System

SOFBALL Structures of Flameballs at Low Lewis Numbers

STS Space Transportation System 


\section{INTRODUCTION}

Many common, gravity-related phenomena are taken for granted, such as a helium balloon rising, bubbles rising in a pot of boiling water, the flat surface of a cup of coffee, and a stone sinking in a pond. Buoyancy and sedimentation occur due to the stratification effect of gravity on materials of different densities. The phenomena of many physical science experiments are adversely affected by buoyancy and sedimentation. Consequently, some science experiments are routinely placed in a microgravity environment where such gravitational effects are drastically reduced.

The apparent removal of the dominant $1-\mathrm{g}$ force in a microgravity environment results in weaker forces, such as surface tension, becoming significant. While the drastic reduction of the $1-\mathrm{g}$ effects is desirable to make weak forces more observable, mechanical vibrations from outside sources become significant and undesirable disturbances. Even though these disturbances are low in magnitude, they can be comparable to forces being investigated, such as surface tension. Therefore, the mechanical disturbances to which microgravity experiments are exposed need to be measured and considered in the analysis of the science data.

\section{NOT JUST GRAVITY}

Gravitational force is not the only force that is desirable to eliminate or reduce by conducting an experiment in a microgravity environment. Disturbances to experiments on the ISS may be caused by other forces, such as vibrations (e.g. pumps and fans), steady forces (e.g. atmospheric drag), and transient phenomena (e.g. valve operation). The magnitude of these forces range from 0.01-g (briefly for a thruster jet) to below onemillionth of $1 \mathrm{-g}$ (prolonged for atmospheric drag in orbit).

The impact of these disturbances are many and varied. Vibrations can cause non-linear effects in fluids, especially in fluids with mixtures of different density components, such as gas bubbles in a liquid. Mechanical vibrations may introduce significant energy into a cryogenic sample. Steady or nearly-steady (so called quasi-steady), low-level accelerations can cause sedimentation and/or convection in fluids with vastly different densities such as in a molten semiconductor compound in a furnace.

\section{EFFECTS ON EXPERIMENTS}

Only a few experiments are satisfied with an acceleration environment where only the gravitational force has been drastically reduced. Many of these are biological experiments where the time constants of change are hours, days, or weeks in which the integrated effects of 1-g dominates the integrated effects of the smaller forces.

Effects occur when unbalanced forces cause motion, quite often in experiments involving fluids, which are involved in nearly every microgravity science experiment. Fluids exist in microgravity experiments in the form of liquids (e.g. silicone oils and semiconductor melts), gases (e.g. hot combustion products), critical fluids (e.g. liquid helium), and granular solids.

Detrimental effects of fluid motion caused by external accelerations may appear to be due to scientific phenomena. Acceleration-driven convective flow in the Surface-Tension Driven Convection Experiment would have drastically reduced the science return. ${ }^{1}$ During experiment operations on Space Transportation System (STS) -50, external-sourced vibrations were observed to cause drastic effects in the fluid sample chamber.

Knowledge of the acceleration environment is critically important for most microgravity experiments, whether the knowledge is from predictive analyses or from real-time measurements of the actual environment.

The microgravity environment requirements for classes of microgravity science payloads were collected to reaffirm the need for the ISS programmatic microgravity environment requirements. ${ }^{2}$

\section{ACCELERATION AS A PARAMETER}

Experiment and/or facility design incorporates parameter measurement (e.g. pressure and temperature) into the design of the experiment in unique methods according to the requirements of the experiment. In some cases, the design of such diagnostics is an engineering and scientific pursuit of its own.

Measurement of the acceleration environment for NASA microgravity space experiments was assigned to the NASA Glenn Research Center in 1986. Coupled with that measurement task is the analysis and dissemination of those data, thereby relieving the experiment teams of those specialized functions.

Some researchers measure the acceleration environment of their ground laboratories in order to better understand their experimental results when the experiment has been operated in a microgravity 
environment. Examples of ground laboratory disturbance sources include elevator operations, air conditioning equipment, automobile and truck traffic, and laboratory personnel. Air conditioning equipment operation may be a large contributor to the acceleration environment of a ground laboratory due to the initial starting transients and the continuous vibrations of compressors as well as the disturbances from flowing room air.

Some researchers have used a controlled shaking of their experiment chamber to investigate the susceptibility of their experiment to vibrations. These results may lead to constraints on the design and operation of the experiment.

\section{SUSCEPTIBILITY VERSUS ENVIRONMENT}

The susceptibility of an experiment to acceleration inputs help to determine its acceleration environment requirements. If the experiment has a resonant frequency determined by its mechanical design, its susceptibility for disturbance by an acceleration is high at that frequency. Precautions must be taken to avoid mechanical resonance frequencies of the experiment chamber close to the frequencies of disturbance source frequencies. Such a problem came about during operations of the Fourth United States Microgravity Payload, one of two major payloads on STS-87. During the mission, vibrations from the thermal subsystem fans within one of the four experiments was found to interfere with the adjacent experiment, the Confined Helium Experiment. Real-time analysis during the mission resulted in compensation applied to the data from the affected experiment to counter the energy input from the vibrations. ${ }^{3,4}$

On the other hand, if an experiment is found to be susceptible to disturbances, it may not be possible to compensate the experimental data nor modify the design of the experiment or disturbance source. In some cases, an operational remedy may be needed where the experiment is operated when the disturbance source is not present. The Structures of Flameballs at Low Lewis Numbers (SOFBALL) combustion experiment was found to be very susceptible to acceleration disturbances from Shuttle thrusters firing during the STS-94 mission. After this was discovered, the researcher requested that thruster jets be inhibited during future experiment operations of SOFBALL. ${ }^{5}$ Figure 1 shows the effect of thruster firings had on the thermal radiation levels. The remedy in this case was possible because the SOFBALL experiment operations were short ( $<2$ minutes) since the Shuttle operational requirements would not allow longer time periods with inhibited thrusters.

\section{VIBRATION ISOLATION}

Early in the development stages of the ISS, requirements were introduced into the ISS program to ensure a quiet microgravity environment for extended periods of time. Figure 2 summarizes these requirements which are contained in ISS program documentation. ${ }^{6}$ Even though the ISS components and major elements have been designed, analyzed, and tested to meet these requirements, an active isolation mechanism was required at payload locations to reduce the disturbances to a level below that of the requirements. The Active Rack Isolation System (ARIS) provides mechanical isolation between an entire ISS payload rack and the rest of the ISS vehicle so that minimal vibrations are transmitted from the vehicle to the experiment payloads on that rack. ${ }^{7}$

There are other isolation systems designed for payload-level, experiment-chamber isolation. A vibration isolation system of this nature may be optimized for the experiment apparatus structural dynamics and the experiment phenomena's dynamics. Such systems may also provide an experiment with a programmed amount of vibration for sensitivity studies or for pre-mixing materials for an experiment.

\section{ISS ENVIRONMENT}

The Principal Investigator Microgravity Services (PIMS) project has developed standard methods of presenting the results of microgravity acceleration data. Assistance in understanding these data plots is available

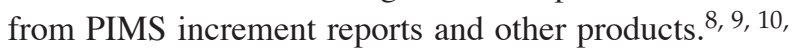
${ }^{11}$ In many of the vibratory regime plots, the levels from the ISS requirements document ${ }^{6}$ are shown for comparison with the actual or predicted environment. For explanations of the ISS environment to date, consult the PIMS increment reports. ${ }^{11,12,13,14}$

The ISS operations have been designed in accordance with the long-standing requirements on acceleration levels at payload locations. During microgravity operational intervals of 30 days minimum, the ISS will be operated so the payload locations will encounter an acceleration environment at or below the levels specified in the requirement. ${ }^{6}$ All components of the ISS, including payloads, are subject to these requirements, the 
only exceptions are some crew actions and safety contingencies.

The Boeing Company, the ISS prime contractor, is performing formal analyses to show that the ISS will meet the microgravity environment requirements. Results from current analyses show that the ISS will meet most of the microgravity environment requirements when the ISS assembly is complete. ${ }^{15,16,17}$ The results show an exceedance in the quasi-steady regime where only 14 rack locations (16 are required) are in compliance. ${ }^{15}$

The ARIS ISS Characterization Experiment (ARISICE) tests were conducted on the ISS from June 2001 to June 2002 and again through November 2002. The results demonstrated that the ARIS system will be effective in reducing the transmission of vibrations from the ISS to payloads in ARIS-equipped racks (Figure 3). ${ }^{7}$

The Space Acceleration Measurement System (SAMS) data from the ISS indicates a trend that the environment will meet requirements when the assembly is complete and microgravity operational conditions are imposed. The data included in the analysis of Figure 4 represents a relatively quiet period of ISS operations although the ISS is not yet operated in a strict microgravity mode of operation. This plot shows the environment to be below the required levels across most of the spectrum for the vast majority of the time.

The Microgravity Acceleration Measurement System (MAMS) data from the ISS indicates that the quasisteady environment will not meet the formal requirements either by the number of racks and/or acceleration levels. Utilizing MAMS quasi-steady data, a PIMS analysis estimated the acceleration levels for each payload rack location for the ISS configuration at Assembly Complete, Figure 5. This shows that no racks (as opposed to the 16 specified by the requirements) will have the required quasi-steady levels. However, for most of the racks, the numeric deviation of the perpendicular components with respect to the requirements approaches the accuracy of the MAMS data. Additionally, no attempt was made to adjust for the difference in drag effects or ISS principal axis offset at Assembly Complete. These factors can affect the outcome of the analysis significantly.

The ISS Program has periodically prepared an analysis of the vibratory acceleration environment of the ISS non-isolated racks. This is the environment seen by a payload mounted in the laboratory module, but outside of an ARIS rack. Preliminary results from the Non-
Isolated Rack Assessment predict, at Assembly Complete, the levels shown in Figure $6 .{ }^{18}$ These levels are shown with the ISS vibratory requirement levels as a comparison, but it must be noted that the ISS is not required to meet these levels outside of the ARIS racks. As explained earlier, the ARIS will reduce the nonisolated rack levels for the payloads mounted in ARISequipped racks.

These various analyses will be updated as the ISS is constructed further and the microgravity environment changes accordingly. Measured data will continue to be compared with analyses.

The PIMS ISS environment analyses to date have primarily concentrated on identifying the source of the disturbances seen in the measured data. These disturbances include vehicle docking, reboost, subsystem equipment, payload equipment, crew actions (e.g. exercise and extra-vehicular activity), venting, and vehicle orbital attitude. Many of these disturbances will not be present during microgravity mode operations by definition of that operational mode. These analyses will result in an understanding of the environment (in particular, the sources of disturbance) in preparation for ISS payload support during microgravity mode operations after ISS Assembly Complete.

\section{MICROGRAVITY ENVIRONMENT INTERPRETATION}

The PIMS project offers educational opportunities to principal investigators and their team members to better understand the microgravity environment and its influence on their experiment. The Microgravity Environment Interpretation Tutorial ${ }^{8}$ is offered annually at the NASA Glenn Research Center with no registration fee for this three day tutorial. The participants acquire a better understanding of the microgravity environment and are therefore better prepared for conducting their experiments in a microgravity environment or supporting those who do.

The PIMS project analyzes acceleration data from the SAMS and the MAMS instruments on-board the ISS in order that the microgravity environment may be understood and possibly correlated with science experiment results. A real-time computer system receives the SAMS and MAMS data streams and processes standard data plots which are made available for all users on the World Wide Web. ${ }^{19}$ The PIMS analysis results are published in periodic reports of the

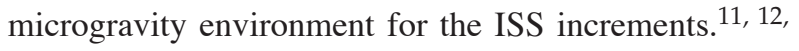


13, 14 Events during the operation of the ISS are included in these analyses, such as vehicle docking, extravehicular activity, reboost operations, and experiment operations.

For measurements during experiment operations, the SAMS and PIMS projects can help plan the acquisition of appropriate acceleration data. If necessary, arrangements may be made to install a SAMS sensor on or near an experiment, PIMS can then provide standard and custom analyses of the measured data for the PI team.

\section{SUMMARY}

The ISS microgravity environment appears to be oncourse for levels as required and planned for microgravity science experiment operations on the ISS.

The PIMS, SAMS, and MAMS teams are chartered to support the microgravity environment needs of the PI teams. For current and/or future support, contact PIMS now.

\section{REFERENCES}

1) Line, A., Zurawski, R., Jacobson, T., Kamotani, Y., and Ostrach, S., "Hardware and Performance Summary of the Surface Tension Driven Convection Experiment-2 aboard the USML-2 Spacelab Mission," 47th IAF Congress, Beijing, China, October 1996.

http://microgravity.grc.nasa.gov/stdce2/ iaf10906/iaf1096.htm

2) DeLombard, R., "Microgravity Requirements for Scientific Research on the International Space Station," Technical white paper, 1999. http://microgravity.grc.nasa.gov/MSD/ UG_ISS_RQMT/index.html

3) DeLombard, R., Hrovat, K., and McPherson, K., "Experiment-to-Experiment Disturbance of Microgravity Environment," NASA TM-1998-208847 / AIAA-990576, December 1998.

4) DeLombard, R.: Disturbance of the microgravity environment by experiments, AIP Conference Proceedings Vol 504(1) pp. 614-618. January 19, 2000

5) Moskowitz, M. E., Hrovat K., Tschen, P., McPherson, K., Nati, M., and Reckart, T. A., "Summary Report of Mission Acceleration Measurements for MSL-1,"NASA/ TM-1998-206979, 1998.

6) SSP 41000, System Specification for the International Space Station, NASA JSC

7) Allen, J. L., Bushnell, G. S., and Fialho, I. J., “Active Rack Isolation System ISS Characterization Experiment (ARIS-ICE) Final Report,” D684-11701-01, September 15, 2003.
8) Participant package for annual Microgravity Environment Interpretation Tutorial

http: //WwW.lerc.nasa.gov/WWW/MMAP/PIMS/ MEIT/meit2002pdfs.html

9) Rogers, M. J. B., Hrovat, K., McPherson, K., Moskowitz, M. E., and Reckart, T.: Accelerometer Data Analysis and Presentation Techniques, NASA TM-113173, September 1997.

10) DeLombard, R.; K. McPherson; Moskowitz, M.; and Hrovat, K.: Comparison Tools for Assessing the Microgravity Environment of Missions, Carriers and Conditions, NASA TM-107446, 1997.

11) Jules, K., Hrovat, K., Kelly, E. M., McPherson, K. M., and Reckart, T. A., "International Space Station, Increment-4/ 5 Microgravity Environment, Summary Report (December 2001 to December 2002)," NASA/TM2003-212460, 2003.

12) Jules, K., Hrovat, K., and Kelly, E., ISS Increment-2 Quick Look Report: May to June 2001, NASA TM-2001211200, 2001.

13) Jules, K., Hrovat, K., Kelly, E. M., McPherson, K. M., and Reckart, T. A., "International Space Station Increment-2 Microgravity Environment Summary Report (May to August 2001)," NASA TM-2002-211335, January 2002.

14) Jules, K., Hrovat, K., Kelly, E. M., McPherson, K. M., Reckart, T. A., and Grodsinksy, C., "International Space Station Increment-3 Microgravity Environment Summary Report (August to December 2001),"NASA/TM-2002211693, 2002.

15) Laible, M. R., "Verification Analysis Cycle Assembly Complete (VACAC) Analysis: Vehicle Quasi-steady Microgravity Compliance," The Boeing Company memorandum J332-2002-117, November 22, 2002.

16) Laible, M. R., Scheer, S. A. and Thampi, S., Verification Analysis Cycle Assembly Complete (VACAC) Analysis: Structural Dynamic Microgravity Assessment," The Boeing Company memorandum J332-2002-118, November 22, 2002.

17) O'Keefe, E., "Assembly Complete Verification Analysis Cycle (VAC) Analysis: Vibroacoustics Compliance," The Boeing Company memorandum J332-2002-116, September 27, 2002.

18) Personal communication with William Hughes, NASA Glenn Research Center, Cleveland, Ohio.

19) PIMS real-time ISS microgravity environment data on the World Wide Web:

http://pims.microgravity.grc.nasa.gov/st 


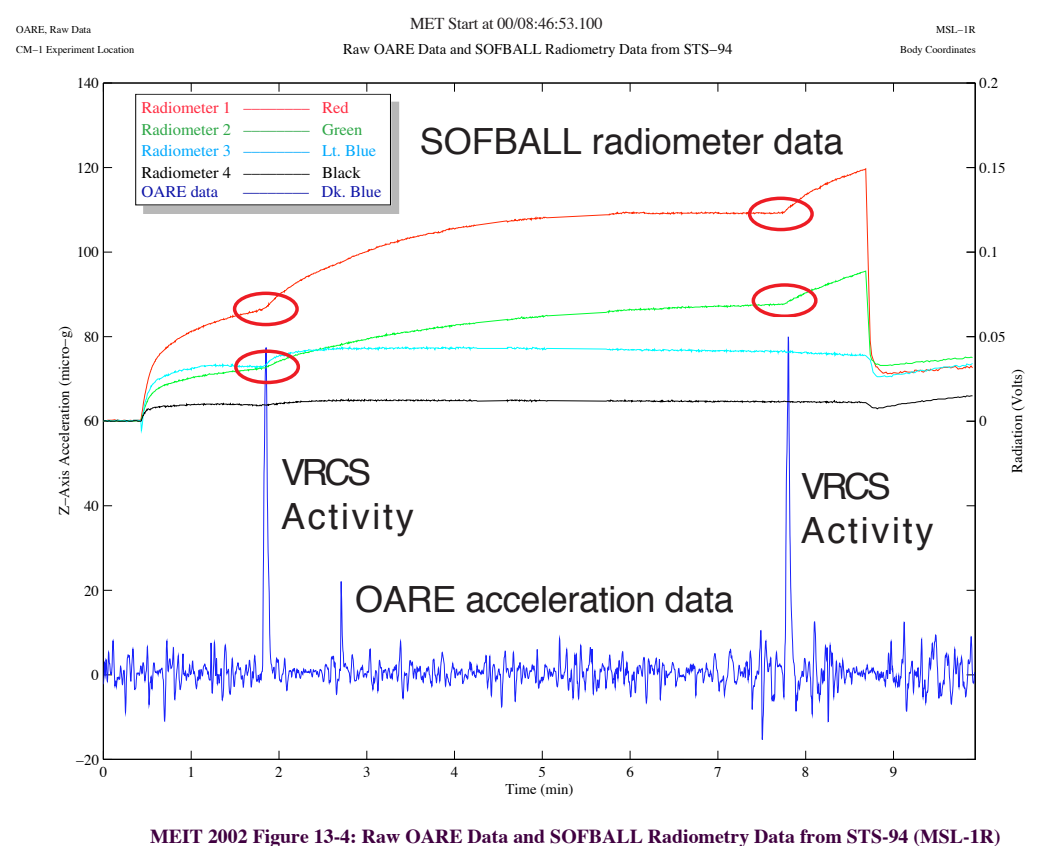

Figure 1: SOFBALL radiometer data affected by thruster firings. Ovals indicate changes in radiometer data as a result of the accelerations experienced from the Orbiter's Vernier Reaction Control System (VRCS) thrusters firing. ${ }^{5}$

Quasi-steady

- Steady state $<\mathrm{f}<0.01 \mathrm{~Hz}$

- $\mathrm{g} \equiv 1 \mu \mathrm{grms}$

- Stability: perpendicular $\mathrm{g} \equiv 0.2 \mu \mathrm{g} \mathrm{gms}$

Vibratory

- Levels in figure at structural

mounting interfaces

- RMS acceleration magritude in onethird octave averaged over 100 seconds

- Does not indude crew disturbances

\section{Transient}

- $g=1000 \mu \mathrm{g}$ per axis

- $\mathrm{g} \leq 10 \mu \mathrm{g}$-sec per axis (integrated over $10 \mathrm{sec})$

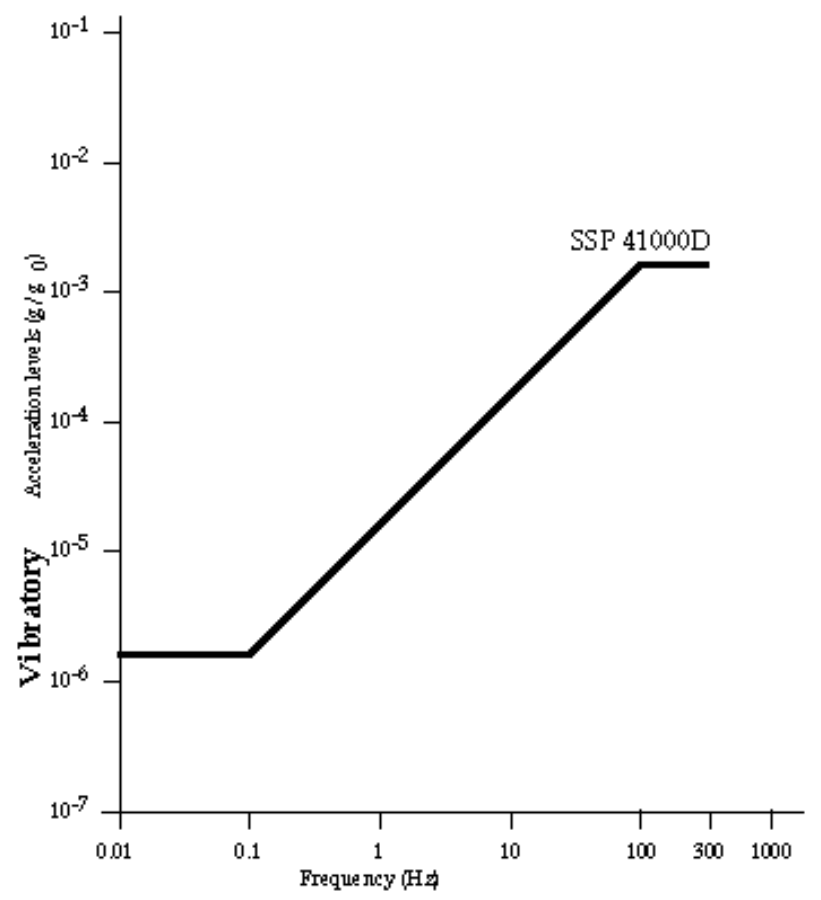

Figure 2: ISS microgravity requirements summarized from ISS program documentation. The microgravity operations will be during 30 day (minimum) intervals with a total of 180 days per year. ${ }^{6}$ 


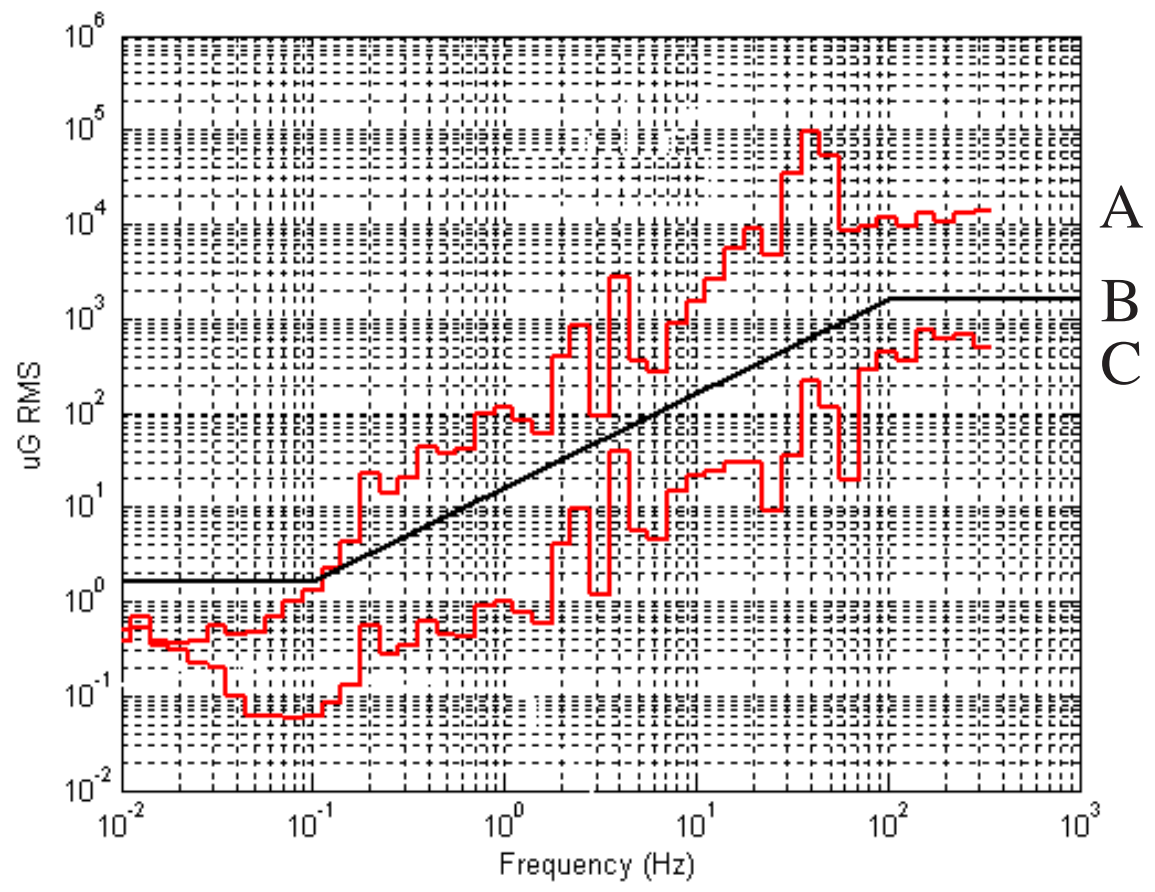

Figure 3: Typical measured acceleration levels during ARIS-ICE operations. Line A is the vehicle off-board environment. Line B is the ISS programmatic requirement level for the vibratory regime. Line $\mathrm{C}$ is the environment on-board an ARIS rack. ARIS reduces the off-board levels to on-board levels which are lower than the required environment levels. (ARIS-ICE data processed by The Boeing Company. ${ }^{16}$ )

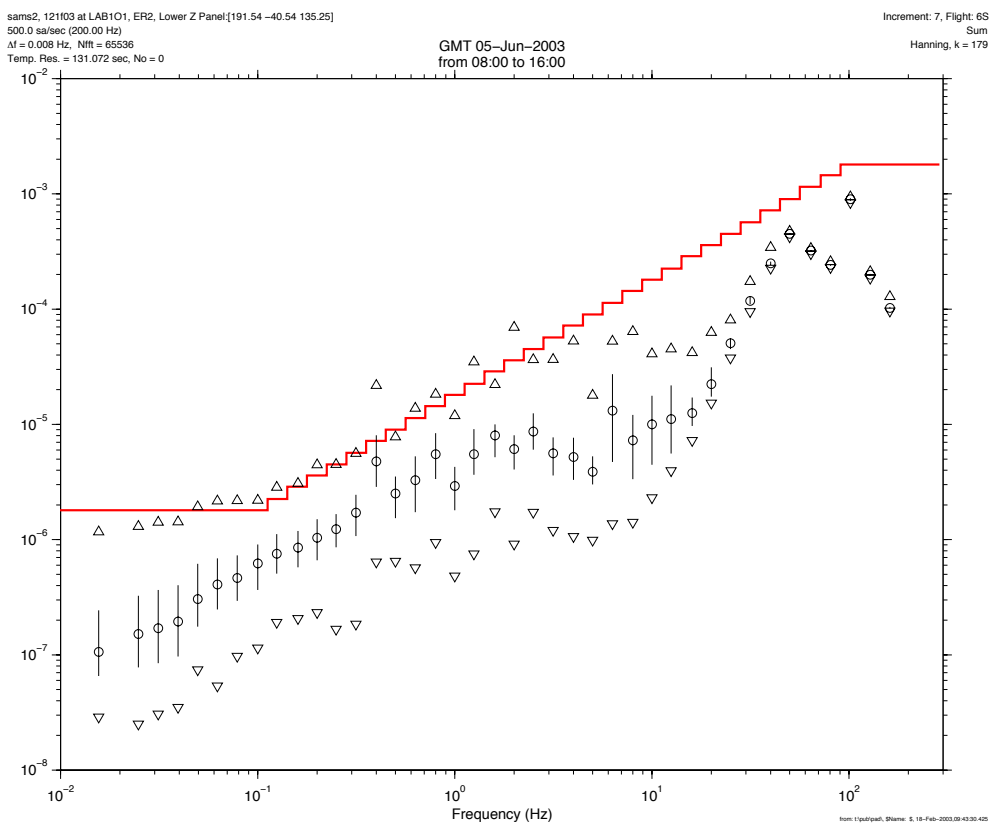

Figure 4: One-third-octave quartile plot of ISS vibratory environment during nominal crew activities on June 5, 2003. The upper symbol in each one-third octave is the maximum value, the vertical line indicates 25 to 75 percentile, and the lower symbol is the minimum value. The circle indicates the median of the data for each one-third octave band. The ISS vibratory requirement level is shown for comparison. (SAMS data processed by PIMS.) 

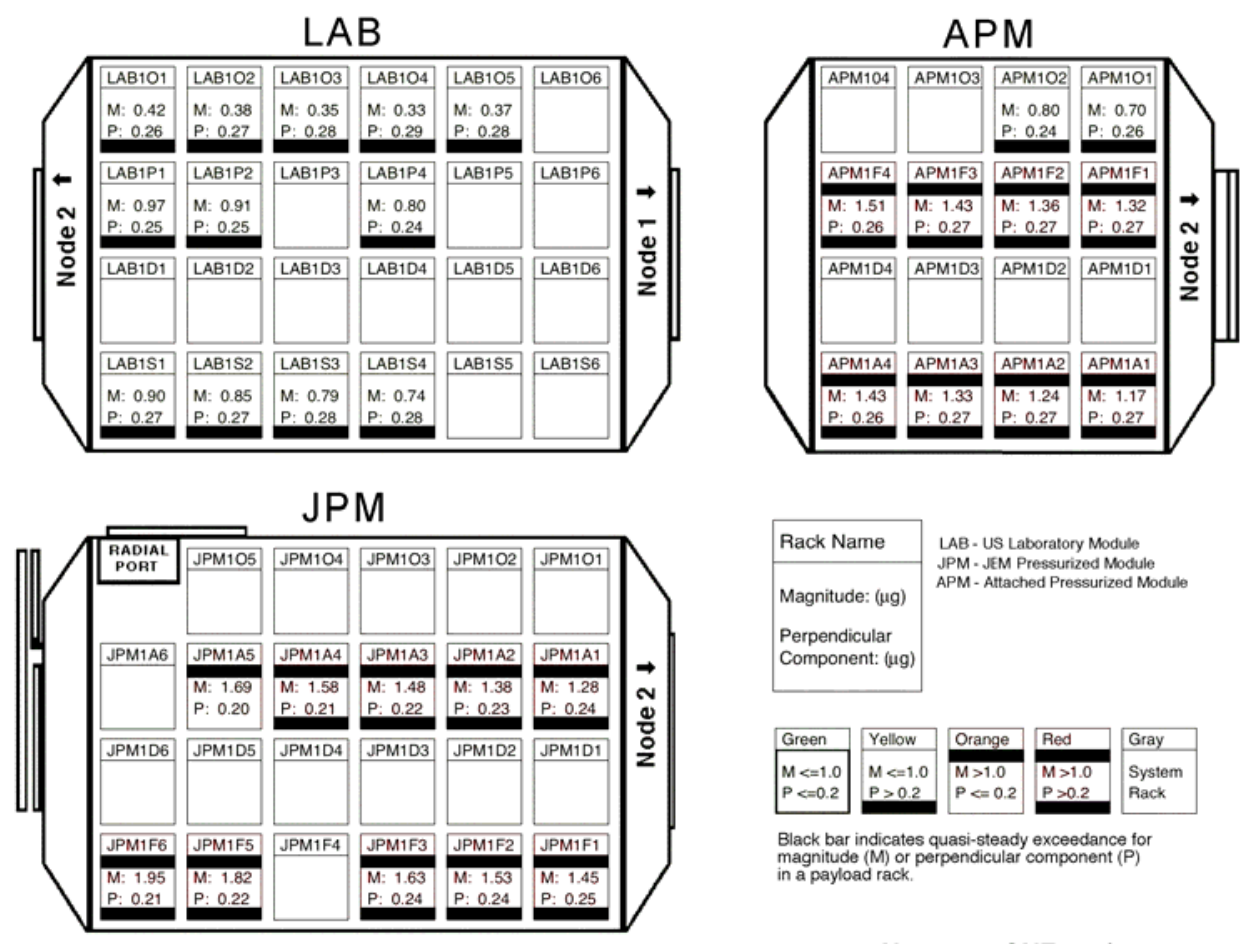

15-May 2002, GMT 135/ 03:00:00

Figure 5: Quasi-steady acceleration levels predicted for Assembly Complete in the U.S. Laboratory module, Destiny. The black bar in the rack location graphic denotes exceedance of the requirement for either magnitude or the perpendicular component. (PIMS analysis of MAMS data.)

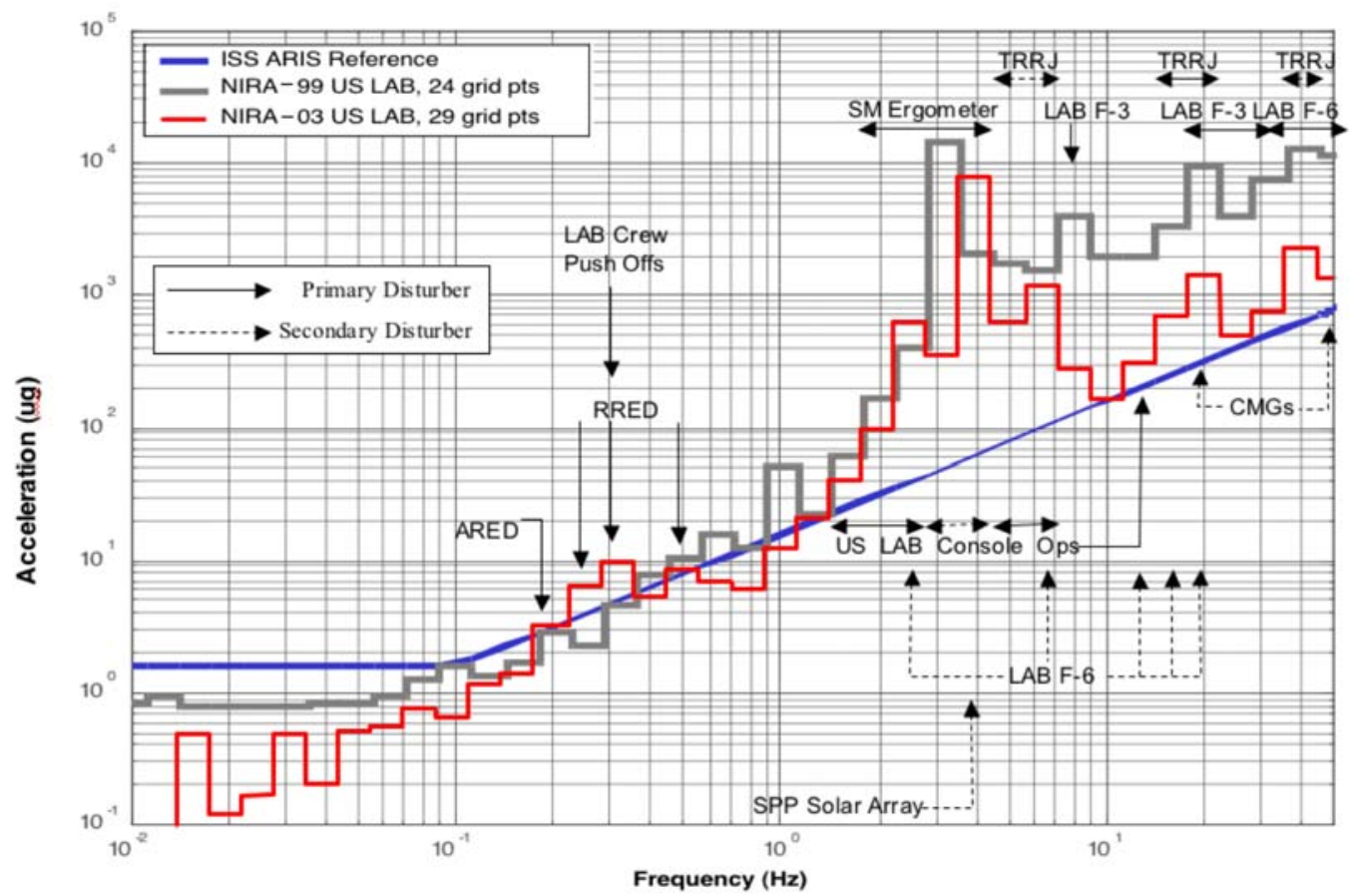

Figure 6: Preliminary assessment of vibratory environment of a non-isolated rack in the ISS Destiny laboratory module. ${ }^{18}$ 
Public reporting burden for this collection of information is estimated to average 1 hour per response, including the time for reviewing instructions, searching existing data sources, gathering and maintaining the data needed, and completing and reviewing the collection of information. Send comments regarding this burden estimate or any other aspect of this collection of information, including suggestions for reducing this burden, to Washington Headquarters Services, Directorate for Information Operations and Reports, 1215 Jefferson Davis Highway, Suite 1204, Arlington, VA 22202-4302, and to the Office of Management and Budget, Paperwork Reduction Project (0704-0188), Washington, DC 20503.

\begin{tabular}{|l|l|l}
\hline 1. AGENCY USE ONLY (Leave blank) & $\begin{array}{c}\text { 2. REPORT DATE } \\
\text { April } 2004\end{array}$ & $\begin{array}{r}\text { 3. REPORT TYPE AND DATES COVERED } \\
\text { Technical Memorandum }\end{array}$ \\
\hline
\end{tabular}

4. TITLE AND SUBTITLE 5. FUNDING NUMBERS

Microgravity Environment on the International Space Station

6. AUTHOR(S)

WBS-22-101-46-02

Richard DeLombard, Kenneth Hrovat, Eric Kelly, and Kevin McPherson

7. PERFORMING ORGANIZATION NAME(S) AND ADDRESS(ES)

National Aeronautics and Space Administration

John H. Glenn Research Center at Lewis Field

Cleveland, Ohio 44135-3191

8. PERFORMING ORGANIZATION REPORT NUMBER

E-14473

9. SPONSORING/MONITORING AGENCY NAME(S) AND ADDRESS(ES)

National Aeronautics and Space Administration

Washington, DC 20546-0001

10. SPONSORING/MONITORING

AGENCY REPORT NUMBER

NASA TM-2004-213039

AIAA-2004-0125

\section{SUPPLEMENTARY NOTES}

Prepared for the 42nd Aerospace Sciences Meeting and Exhibit sponsored by the American Institute of Aeronautics and Astronautics, Reno, Nevada, January 5-8, 2004. Richard DeLombard and Kevin McPherson, NASA Glenn Research Center; and Kenneth Hrovat and Eric Kelly, ZIN Technologies, Inc., Brook Park, Ohio 44142. Responsible person, Richard DeLombard, organization code 6727, 216-433-5285.

12a. DISTRIBUTION/AVAILABILITY STATEMENT 12b. DISTRIBUTION CODE

Unclassified - Unlimited

Subject Category: 19

Distribution: Nonstandard

Available electronically at http://gltrs.grc.nasa.gov

This publication is available from the NASA Center for AeroSpace Information, 301-621-0390.

13. ABSTRACT (Maximum 200 words)

A primary feature of the International Space Station will be its microgravity environment - an environment in which the effects of gravity are drastically reduced. The International Space Station design has been driven by a long-standing, high-level requirement for a microgravity mode of operation. Various types of data are gathered when science experiments are conducted. The acceleration levels experienced during experiment operation should be factored into the analysis of the results of most microgravity experiments. To this end, the Space Acceleration Measurement System records the acceleration levels to support microgravity researchers for nearly three years of International Space Station operations. The Principal Investigator Microgravity Services project assists the experiments' principal investigators with their analysis of the acceleration (microgravity) environment. The Principal Investigator Microgravity Services project provides cataloged data, periodic analysis summary reports, specialized reports for experiment teams, and real-time data in a variety of user-defined formats. Characterization of the various microgravity carriers (e.g., Shuttle and International Space Station) is also accomplished for the experiment teams. Presented in this paper will be a short description of how microgravity disturbances may affect some experiment classes, a snapshot of the microgravity environment, and a view into how well the space station is expected to meet the user requirements.

14. SUBJECT TERMS

Acceleration; Measurement; Microgravity; Space station 14

\begin{tabular}{|c|c|c|}
\hline $\begin{array}{c}\text { 17. SECURITY CLASSIFICATION } \\
\text { OF REPORT } \\
\text { Unclassified }\end{array}$ & $\begin{array}{c}\text { 18. SECURITY CLASSIFICATION } \\
\text { OF THIS PAGE } \\
\text { Unclassified }\end{array}$ & $\begin{array}{c}\text { 19. SECURITY CLASSIFICATION } \\
\text { OF ABSTRACT } \\
\text { Unclassified }\end{array}$ \\
\hline
\end{tabular}

NSN 7540-01-280-5500

Standard Form 298 (Rev. 2-89) 

